\title{
Opportunities and Challenges in Implementing Pollution Prevention Strategies to Help Revive the Ailing Carpet Manufacturing Sector of Nepal
}

\author{
Rajeeb Gautam ${ }^{1}$, Sumit Baral ${ }^{2}$, Sunil Herat ${ }^{3 *}$ \\ ${ }^{1}$ : PhD Candidate, Department of Chemical and Biochemical Engineering, University of \\ Western Ontario, London, Ontario, N6A 5B9, Canada, Ph 15196612111 Ext. 81288, \\ Fax 1519661 3498, email rgautam@uwo.ca. \\ ${ }^{2}$ : Manager, Information Management and Planning (Research), Nepal Tourism Board, \\ Tourist Service Center, Bhrikuti Mandap, Kathmandu, Nepal, P.O. Box 11018, Ph 9771 \\ 256909/256229/256230 Ext. 124, Fax 9771 256910, email sbaral@ntb.org.np. \\ 3: Senior Lecturer, Griffith School of Engineering, Griffith University, Brisbane, \\ Queensland 4111, Australia, Ph 6173735 6682, Fax 6173735 7459, email \\ s.herat@griffith.edu.au. \\ *: Corresponding author.
}




\begin{abstract}
Nepal's carpet sector is one of the main economic contributors that plays a significant role in many areas of the country's well being. However, this sector has seen a major downturn in recent years that is related to resource constraints, environmental problems and management inefficiency. Implementation of pollution prevention strategies has brought significant changes in similar sectors elsewhere in the world. Therefore, Nepal's carpet sector can also benefit from such strategies. This paper is written to provide an overview of the problems that the carpet manufacturing sector of Nepal faces. It also provides recommendations to the government, public and the carpet sector on some of the pollution prevention methods that can be implemented in Nepal to revive the ailing carpet sector. The information presented in this paper will also be useful to similar other industries elsewhere in the world that are directly or indirectly involved in carpet sector.
\end{abstract}

Key words: Nepal; Carpet; Pollution prevention; Environment 


\subsection{Introduction and Background}

Nepal is a landlocked country situated between China in the north and India in the south with a total area of 147,181 square kilometers (CBS, 2003). According to the 2001 census, the population of Nepal is approximately 22.7 million which is annually growing at an average rate of $2.25 \%$. The vast majority of the people live in rural areas.

Approximately 14.2\% of the people live in urban centers (CBS, 2003). The 2004 estimate of gross domestic product (GDP) was approximately US\$ 7.4 billion (MOF, 2005). The GDP is mainly composed of agriculture (39\%), industry (8\%), and service (53\%) (MOF, 2005). Some of the primary industries are carpet, textile, cigarette, cement, and brick. Quartz, timber, hydropower, lignite, copper, cobalt and iron are some of the natural resources (JICA, 1998).

Historically, different kinds of weaving practices existed in Nepal in the form of making varieties of mats and clothing from hay and other natural fibers. There are no written records to give information on when weaving ${ }^{\mathrm{i}}$ actually began in Nepal. The development of an organized form of hand knitted woolen carpet manufacturing practice at an industrial scale actually began in the fifties and sixties through the influx of Tibetan refugees. The Swiss Agency for Technical Assistance (SATA) and the United Nations (UN) provided the required financial and technical support to the skilled Tibetan refugees

\footnotetext{
${ }^{\mathrm{i}}$ In this paper, only hand knitted carpets produced from natural wool fiber, such as lamb's wool, are considered. Synthetic carpets made from plastic based materials are not presented in the discussion.
} 
in order to resettle them (CCNA, 2003; Newar, 2004). This was actually the beginning of an organized carpet manufacturing practice in Nepal. The first consignment of carpets that were made in Nepal was shipped to Switzerland in 1964 (CCNA, 2003).

The Nepalese carpet manufacturing sector experienced an unprecedented growth in a short time and became one of the largest industrial sectors to support the country's economy. There are more than 300,000 workers employed in this sector (TRN, 2003) and Nepali carpet is exported to more than sixty countries around the world. Nepal enjoys almost 10\% share of the global carpet market (UNIDO, 2002). Table 1 shows carpet export data to three western countries and all others (in the order of market share) in the 2004/2005 fiscal year (KP, 2005). According to the Carpet and Wool Development Board (CWDB) (CWDB, 2006), there are more than 700 carpet manufacturers, which export carpet from Nepal. The total investment cost of the Nepalese carpet manufacturing infrastructure is approximately estimated at US\$ 261 million at the current market price. The cost breakdown is shown in Table 2 .

In recent years, the Nepal carpet industry has seen a drop both in terms of export quantities and foreign revenue earnings. Figure 1 shows that almost $50 \%$ of carpet exports has declined in terms of carpet area from 1993 to 2005 (CCIA, 2003).

Such a declining trend has serious implications on various sectors of the Nepalese economy. As more than 300,000 workers are directly or indirectly employed in this sector, a decrease in export also means loss of valuable jobs (TRN, 2003). The declining 
trend has been attributed to many problems that are related to pollution, mismanagement, bad publicity, lack of coordination, unplanned growth, poor production planning, etc. Since the carpet industry is one of Nepal's major economic contributors, any kind of set back to this sector is harmful to the country's economy.

One of the ways to improve the current situation is by implementing pollution prevention strategies. Implementation pollution prevention methods in similar sectors in many other countries has shown positive results. Hence, this paper is written to provide a general overview on Nepal's carpet sector and recommend pollution prevention strategies that may bring about good changes in the foreseeable future. This paper also presents two case studies to show how some carpet related companies were benefited by implementing similar methodologies.

\subsection{General Carpet Manufacturing Process in Nepal}

This section provides a brief overview of the general carpet manufacturing process used in Nepal along with different waste streams associated with each stages of processing. Figure 2 presents a simplified flow chart of the manufacturing process. At the time of writing this article, several carpet manufacturing companies were contacted and information on the effluent parameters was requested. However, it was not possible to obtain such information. Therefore, different literature sources were used to quantify some of these parameters as presented below. 
Crude wool: Unprocessed wool from different countries (Tibet, New Zealand, England, Egypt etc.) is imported to Nepal. Such wools come in bales packaged in paper and plastic wraps of varying sizes. The majority of waste is in the form of solid packaging materials, which is usually sold to local recycling companies.

Wool sorting and washing: The wool is then hand sorted to remove foreign matters such as any unwanted debris. This wool is then washed to remove dirt, oil and grease and sun dried for two to three days in open spaces. Both water and air borne suspended solids (SS) are produced in the process. There is a lack of data to quantify the different water quality parameters such as biochemical oxygen demand (BOD), dissolved oxygen (DO), total suspended solids (TSS), chemical oxygen demand (COD), total oil and grease (TOG) that are associated with this stage of carpet processing. However, some of the studies (Green, 2003; Sharma et al., 2005) on the surface and groundwater quality of the Kathmandu Valley report that the carpet manufacturing industries lack effluent treatment facilities, which result in the pollution of surface and groundwater resources of the Valley.

Carding: Washed wool is brushed using metal brushes to prepare it for spinning and weaving. The carding process allows the fiber to flow smoothly at the time of spinning. At this stage, wool from different origins are blended and mixed at proper ratios to gain the specific quality of carpet desired. Traditionally, carding used to be performed by hand and it was very labor intensive. More recently, many of the industries are using 
automated machines for carding. Air borne solid woolen particles are produced in this process, which often cause indoor air pollution.

Spinning: Spinning is a process by which carded wool is spun into yarn using a hand spinning wheel. Machine spinning wheels are not very widely used in Nepal. The quality of carpet depends on the thickness of yarn. Mostly 3 ply yarn is used in Nepal. The waste stream of the spinning process contains small solid yarn pieces, which are reused and recycled on site to make inferior quality carpets so that there is no loss of the raw material.

Dyeing: Two different dyeing methods (pot and machine dyeing) with both vegetable and chemical coloring substances are used in Nepal. The dyeing substances are both imported or locally produced depending on the requirement. The machine dyeing process consists of processing yarns in closed chambers while the pot dyeing process is more traditional and uses locally made open pots for dyeing. After dyeing, the dyed yarn is dried mostly in sunlight for one to three days and taken for further processing. One study (Green, 2003) reports that the process of dyeing produces wastewater that usually contains dyeing chemicals. Some of these dyeing chemicals include acetic acid, sulfuric acid, heavy metals (hexavalent chromium, cobalt, copper) and sodium sulfate (also known as glauber salt). The wastewaters containing these chemicals are directly discharged into the nearby rivers, which has resulted into increased pollution levels. For example, several studies report alarming levels of COD, BOD and DO at 325, 40 and 1 
mg/l, respectively (Green, 2003; Pradhan, 2000; Karn and Harada, 2001) in the Kathmandu Valley rivers, which are linked to carpet industry effluents.

Carpet Knotting: Carpet knotting is done by skilled weavers who follow paper printed graphic designs to make artistic prints. Weaving is done in wooden or metal frames known as looms. Depending on the size of the carpet, the loom size and the number of workers varies between looms. Simple tools such as scissors, iron rods, levers, comb beaters etc. are used by weavers to make individual knots. Fiber cuttings are the main waste products generated in this process. All fiber cuttings are recycled or reused on site to make inferior quality carpet.

Trimming: Finished carpets that are produced in the looms are not of very good quality. They require further finishing by the process of trimming. In this process, the carpets are taken off from the looms and spread on the floors. Then the designs and patterns in the carpets are curved out using scissors. Fiber cuttings are the main waste products generated in this process. All fiber cuttings are recycled or reused on site to make inferior quality carpet.

Finishing: This is the final step in the carpet manufacturing process. The trimmed carpet is mainly washed and dried. Washing is done either with fresh water or chemicals as desired. Some of the chemicals used in the washing procedure are ammonium sulphate, sodium sulphate, acetic acid, dye, detergents, etc. The washed carpet is then dried in sunlight and packed for final dispatch. By the time final finishing is done, the carpet 
industries in the Kathmandu Valley generate approximately 1.6 million cubic meter of untreated wastewater with 355 and 750 tons of BOD and TSS loadings per annum, respectively (Green, 2003; Sharma et al., 2005).

\subsection{Responsible Factors}

As mentioned previously, Nepal's carpet sector is facing many problems, which have contributed to the decline in trade. These factors have been broadly grouped into environment and management related factors.

\subsection{Environmental Factors}

\section{Costly Water Losses}

Many carpet industries are established in an unplanned way in buildings and structures that are unsuitable for industrial purposes. This causes loss of valuable water, which adds to the cost of production. Some of the commonly observed but neglected wastes of water are listed here (Thornton, 2002):

- Leaks through pipes and hoses that go unnoticed or neglected

- Inefficient washing equipment and lack of knowledge of the equipment

- Excessively long washing cycles

- Excessive use of water in washing operations when washing is done manually 
- Poor housekeeping practices such as broken or missing valves

- Cooling waters are left running when machinery is shut down

- Use of fresh water at all points of water use without reusing and recycling

\section{Lack of 3R Principle}

The recovery, reuse and recycling (3R) of process chemicals and water is rarely practiced by carpet manufacturing industries in Nepal. The use of virgin chemicals at every point of use adds to the cost of production. Moreover, this increases the quantity of wastewater requiring treatment. This also exacerbates environmental pollution caused by wastewater discharged into freshwater bodies.

\section{Excessive Use of Dyes}

Nepalese carpet manufacturing industries mostly use synthetic dyes. These dyes are often applied to the carpet fabric in vats that have no automatic process controls. Therefore, efficiency is lost and needlessly large quantities of dyes are used. Such large quantities of dyes often end up in rivers and estuaries and cause detrimental effects on the environment (Hammer, 1998). Loss of large quantities of synthetic dyes also adds to production costs. 


\section{Lack of Knowledge}

The carpet manufacturing sector in Nepal did not flourish due to the presence of organized and planned trading practices. When Western nations showed interest in the carpets manufactured in Nepal during the late eighties and early nineties, a lot of people began to put a few looms in the basement of their homes and started producing carpets on a small scale (Sitaula, 2003). These people became entrepreneurs within a very short time and enjoyed profits that were not imagined before. However, they continued to lack the necessary knowledge of environment, economics, foreign trade, health and safety. This was the reason why the carpet industry started to face a lot of problems within 10 to 20 years of enjoying unprecedented growth.

\section{Resource Shortages}

Most of the carpet manufacturing industries in Nepal are situated within the perimeter of the Kathmandu Valley. It is estimated that almost $90 \%$ of the Nepalese carpet is manufactured inside this valley (Hammer, 1998). The population of the Kathmandu Valley has increased to almost two million and it is showing an increasing trend. This has put a tremendous pressure on the available resources that support industry and infrastructure in the valley. An independent study conducted by the World Bank/Federation of Nepalese Chambers of Commerce and Industry (WB/FNCCI) in 2000 estimated that the carpet industries in Nepal face severe problems in terms of availability 
of water, energy and other related infrastructures (WB/FNCCI, 2000). Table 3 shows some of the areas where carpet industries are facing resource shortages.

As shown in this table, water and energy shortages have forced many of the carpet industries to provide their own service. In order to meet energy demand, carpet industries use diesel run electricity generators. Similarly, water demand is met from underground wells, which are dug within the industry premise. Use of diesel-powered generators has worsened the air and noise pollution of the Kathmandu valley. Similarly, pumping of water from deep aquifers has caused lowering of groundwater levels in the valley. One study shows that the groundwater level in the valley has been lowered from $9 \mathrm{~m}$ below ground level (bgl) to as much as $68 \mathrm{~m} \mathrm{bgl} \mathrm{within} \mathrm{a} \mathrm{few} \mathrm{years} \mathrm{(Metcalf} \mathrm{\&} \mathrm{Eddy,} \mathrm{2000).}$ These aquifers are not being replenished by the natural recharging process. This has led to the drying of many natural springs, waterfalls and ponds in the valley, which have caused significant long term damage to the environment. Moreover, land subsidence problem has also started to be evident in the Kathmandu valley.

\section{Lack of Proper Wastewater Treatment, Recycling or Reusing Facilities}

Most of the Nepalese carpet industries do not have any wastewater treatment, recycling or reuse facilities (TRN, 2003). There is a widespread practice of directly pumping out the wastewater into sewers or surface water bodies such as rivers, lakes and streams without even giving a second thought to the possibility of reusing or recycling. Some of the worst contamination problems have surfaced in many receiving water bodies due to 
this. In the past when there were very few carpet industries, this was of little concern because the adverse effect was not quite visible. However, with the increasing number of industries and the cumulative effect of the pollutants in the ecosystem, it has generated many environmental problems (Adhikary, 2002). For example, in some areas of Kathmandu Valley, the carpet industry has been found responsible for depletion of all forms of aquatic life (NPEDC, 1991). News on such deteriorating environmental quality in the international media has prompted the decreasing trend of carpet exports.

\subsection{Management Related Factors}

\section{Lack of Organizational Infrastructure}

Although carpet manufacturing industries were established in the sixties, for a long time there was not any organization that provided a common platform to co-ordinate policies and activities between the government and the industry. It was only in July 1990 that a fully representative association came into being after the formation of the Central Carpet Industries Association (CCIA) (CCIA, 2003). By this time, environmental and management problems had already started to surface and CCIA was not experienced enough to handle such problems. 


\section{Lack of Regulatory Body}

In Nepal, Ministry of Population and Environment (MOPE) acts as a governmental regulatory body to oversee environment related matters such as environmental conservation, pollution control, environmental standards, enforcement and monitoring, environmental impact assessment etc. MOPE was established fairly recently in 1995. By this time, the carpet sector had already operated for more than 20 years without any governmental regulatory authority that imposes environmental standards. It should be noted that most of the environment related acts and regulations were promulgated only after MOPE was established. For example, Environmental Protection Act (EPA) and Environmental Protection Regulation (EPR) were formulated in 1996 and 1997, respectively. This is one of the reasons why most of the pollution problems caused by the Nepalese carpet sector remained unchecked for many years.

\section{Negative Publicity}

In 1994/1995, the Nepalese carpet industry suffered a huge setback as the export

plummeted by almost 34\% (refer to Figure 1). One of the reasons for this was attributed to the negative publicity that Nepalese carpets were facing due to anti child labor issues in overseas countries. Western nations were mostly concerned about the child labor situation in Nepalese carpet sector and started boycotting Nepalese carpet (USDOL, 2003). 


\section{Excessive Supply and Unplanned Growth}

Since Nepalese carpet sector did not have any organized body until recently to coordinate the marketing issues, there was no control on the industrial practice. Carpet industries sprawled in every possible empty space in the Kathmandu valley. Moreover, there was a lack of institutional involvement in conducting economic studies on the global market trends to make a planned production of carpet. As a result, there was an excessive supply of carpet in the market, which ultimately let to price undercutting in the industry.

\section{Foreign Dependence}

Nepal is heavily dependent on foreign countries in the carpet sector. Almost everything that is used in the industry is imported. Crude wool, dye, chemicals and machinery are all imported either from neighboring countries (India and Tibet/China) or from overseas. Nepal's northern cold climate is ideally suited for sheep farming and wool production. However, concerned authorities have not given thought on this matter. The production of home grown wool would have reduced dependency on the foreign market and it would have also helped in reducing the expenditure of foreign currency.

\section{Tough Competition}

In the past, carpets were produced by very few countries in the world and there was not much competition. However, in the recent years, many new countries have started to 
produce carpets and export their products in a world-wide scale. This has put a tremendous pressure on Nepalese carpet sector due to increasing competition.

\subsection{Need for Pollution Prevention Strategies}

In general, Nepalese carpet sector is facing the following problems:

- Short term oriented goals without considering long term environmental impacts

- Lack of pollution prevention strategies

- $\quad$ Lack of life cycle assessment of products manufactured

- Poor housekeeping practices

- Establishment of open-end systems rather than closed-loop systems and

- Lack of investment on energy saving and improved technologies

One of the ways by which the above problems can be tackled is by implementing pollution prevention related strategies. Although "control' strategies can also be implemented for both short and long term solutions, they are not suitable in Nepal's context (Gautam and Herat, 2000) because such practices are not cost effective. It is also true that the carpet industry decision makers (CIDMs) lack the basic understanding of pollution prevention strategies and principles, which made pollution prevention strategies unpopular. CIDMs do not know that pollution prevention does not necessarily mean a huge investment in technologies and training in complex process changes. It means recognition of the environmental and financial implications of not doing something to 
solve pollution problems, changing corporate attitudes and workers participation, among other things. Therefore, a radical approach is required in order to deal with these problems. Implementation of pollution prevention methods in similar other sectors has already shown many positive results (Dupont et al., 2000). Such pollution prevention methods may also bring positive changes in Nepal's carpet industry sector.

\subsection{Recommendations}

In this section, recommendations are provided that can be implemented to revive the carpet industry. Most of these recommendations are targeted to bring about process or policy modifications with little or no investments. Even if there is any investment, the pay back period will be very short as indicated in Section 6.0, which presents two successful case studies.

\subsection{Recommendations Related to Process Modification}

\section{Detect and Repair Water Leakage}

As mentioned previously, leakages of pipes and plumbing fixtures in Nepalese carpet industries are very common. This can be avoided by employing the following strategies:

- Maintain the piping system regularly and keep maintenance records

- Report leaks immediately 
- Control water loss due to overflow of water reservoir tanks

- Control theft of metering devices and other fixtures by informing staff to be vigilant at all times and asking them to report any theft incidents immediately to the local police

\section{Reduce, Reuse and Recycle Wastewater}

Instead of using fresh water at every point in the manufacturing process, conduct a detailed study to identify if wastewater can be reduced, reused or recycled. Wastewater with high TSS content generated early on during the cleaning of raw wools can be reused by letting it settle in large settling basins. This practice may not even require any investment because carpet industries routinely use large tanks in stocking water. Such tanks can be used as settling basins with very minor modifications in the design. One possible flow diagram that can be implemented by Nepal's carpet industries for this purpose is shown in Figure 3.

\section{Improve Washing Procedure}

The process of washing directly affects the efficiency of how water is used. Therefore, conduct a study to identify what method of applying water is effective in reducing time and increasing efficiency of water use. Similarly, find out from literature sources what temperature is effective in washing. In the case of lack of information, carry out simple tests within the industry with the help of a few interested employees. In general, using hot 
water $\left(90^{\circ} \mathrm{C}\right)$ increases efficiency by almost two fold compared to washing efficiency using cold water. Similarly, avoid using needlessly long contact times and washing cycles. Sometimes modifying the design of a nozzle saves the quantity of water and time used in washing.

In general, industries should spend time in investigating the following issues (Thornton, 2002) and seek improvement in their ongoing practice:

- Method of water application such as spraying, pulsing, cascading, etc. during cleaning

- Water temperature

- Water application per unit weight of carpet or wool

- Contact time

- Intermediate water extraction method such as squeezing, suction, beating, etc

- Number of washes and washing cycle

- Nozzle modification

\section{Establish Automated Controls}

Automatic process controlling devices are effective in controlling the quantity of dyes used in the coloring process. Such control devices inform the technicians when to change the cycle or when to completely discard the water containing dyes. Most of the Nepalese carpet industries do not have any automated control systems and often individuals with 
very little experience take care of dyeing processes, which are prone to errors. Therefore, invest in the automated control devices and equipment.

\section{Promote Vegetable Dyes}

Vegetable dyes are readily biodegradable and they can be treated using simple biological methods within an industrial site. Moreover, vegetable dyes pose less concern to the environment compared to chemical dyes. They can also be produced locally, which will help save foreign currency that is often used in importing costly chemical dyes. Carpets dyed with vegetable dyes have a good reputation and consumers often prefer such carpets (Hammer, 1998). Therefore, the carpet manufacturing sector in Nepal should use vegetable dyes.

\section{Reduce, Reuse and Recovery of Chemicals}

The following three important areas can be used to increase the recovery and reuse of chemicals:

- Reuse dye solutions from dye-bath whenever is possible. Save used dyes in sealed containers for future use wherever applicable.

- Invest in technologies such as ultrafiltration, evaporation and solvent extraction within budgetary constraints. Evaporation or membrane technology allows recovery of caustic chemicals used in the manufacturing process. This has a two pronged 
effect: it can reduce the use of virgin chemicals, which saves raw material costs and it can also reduce wastewater treatment costs because the concentration of pollutants is reduced.

- Select high quality process chemicals so that quality problems such as spotting can be avoided completely.

- Similarly, invest in technologies such as acid cracking, centrifugation and solvent extraction for grease recovery from wool.

\section{Establish Laboratory}

Most of the carpet industries do not have any testing facilities such as a laboratory for carrying out routine water and/or chemical analyses. The testing is mostly done by sending out samples to other laboratories. This type of practice is not cost effective. Most of the tests can be performed using established standard procedures at a very minimum cost. The reagents and equipment can be bought for a minimum price and the procedures do not require highly technical protocols. By training one or two employees in such testing methods, industries can save money. 


\subsection{Recommendations Related to Policy Modification}

\section{Provide Training and Disseminate Information}

At present there is very little knowledge about pollution prevention among carpet industrialists in Nepal. Entrepreneurs have a misconception that pollution abatement processes are costly and detrimental to the economic well being of the industries. However, instead of promoting “control” measures, industries should be trained on "preventive” strategies. Therefore, dissemination of pollution prevention not pollution control information and providing training on a timely basis is essential. CCIA should take the initiative in acquiring information from different parts of the world and should establish a network with foreign companies that implemented similar preventive strategies. Most such methodologies are available free and a lot of information can be easily obtained from the International Cleaner Production Information Clearinghouse (ICPIC). The carpet and textile industries are similar in many ways and there are many examples where textile industries have implemented pollution prevention methodologies to bring about changes in efficiency, reduction in cost and improved environmental stewardship.

\section{Improve Environmental Standards}

For comparison purposes, MOPE and Canadian standards (MOPE, 1995; CCME, 2002) for various pollutants are provided in Table 4. 
As shown in this table, the discharge criteria for all types of pollutants in Nepal are far less stringent than those in Canada. Most of the above parameters are highly toxic to both humans and aquatic life. It is noted that Nepalese carpets are mostly exported to the Western nations that have highly stringent standards. In order to show environmental stewardship and improve the image in the Western nations, Nepalese disposal standards need to be revised. Therefore, improve these standards based on companies' compliance capability and existing regulation enforcement mechanism.

\section{Form Waste Exchange Network}

Balaju Industrial Development Estate (BIDE) is one of the five national industrial sites that is situated in the Kathmandu valley (Gautam and Herat, 2000). BIDE has numerous industries such as sheet metal, iron, battery, chemical fertilizer, etc. Since $90 \%$ of carpet industries are situated in Kathmandu, these industries can reap the benefit by forming a waste exchange network with BIDE and exchanging wastes. Waste generated by one industry may be a valuable raw material for another.

\section{Provide Incentives and Rewards}

Concerned authorities in Nepal should recognize persons or businesses that show good results by providing incentives and rewards. Government should provide tax incentives to industries that implement pollution prevention strategies while industries should reward 
their employees. Tax incentives can be in the form of reduced charges on profits and import/export tariffs.

\section{Conduct Product Life Cycle Assessment}

Life cycle assessment (LCA) provides a complete environmental profile of goods and services (Hendrickson et al., 2006). The LCA consists of each step from acquisition of raw materials through processing, manufacture, use and final disposal of all residuals. This broad framework helps designers identify and reduce the environmental consequences of their designs. Nepal's carpet manufacturing sector has not done any LCA on the carpets that are being manufactured and exported. Therefore, a LCA should be conducted.

\section{Decentralize Industries}

As more than $90 \%$ of the carpet industries are located inside the Kathmandu valley, the existing number of industries inside the valley have already shown severe resource, space and infrastructure constraints. Government and industrialists should start decentralizing this sector. Although there has been some initiatives undertaken along this line by the government, further incentives should be provided to the industries if they want to expand or open new ones outside the valley. This will also have a positive impact on the valley environment as it is not typically suited for large scale industrial establishment due to its topographical setting. The valley is bowl shaped and has an area of only 662 square 
kilometers. Stack emissions tend to remain inside the valley without effective dispersion. Temperature rise and smog problem due to the green house effect is evident in the valley. Air pollution problem has worsened so much in the valley and people use disposable masks to avoid it (Gautam and Herat, 2000). Therefore, government should give special emphasis to decentralize the industries with proper planning.

As it becomes clearer that the present problem in complying with the environmental standards by the carpet manufacturing industries in Nepal is more due to the absence of effective monitoring and control mechanism as well as inability of authority to take stringent actions against the defaulters, than due to the lack of awareness and investment need towards the practice. Owing to these facts, it becomes imperative that in order to enhance the quality of monitoring and controlling mechanism of the environmental standards compliance and to make the regulation cost effective, the government should allocate industrial areas for carpet industries in particular sites rather than letting them scattered in various places. This would not only make the regulation task much easier for the authority, but also instill sense of competition for the quality among the industries.

\section{Modify Policies}

Nepal needs new policies or modification of the old ones in order to implement the recommendations mentioned above. Some of the areas where new policies are required are occupational health and safety (OHS), sales and marketing, research and development, etc. As can be seen from the foregoing, the child labor issue was a result of 
a lack of proper OHS policies in the carpet industries. Similarly, lack of policies on sales and marketing caused over production and cost undercutting. There is also a lack of policy on research and development to improve carpet manufacturing practices. Hence, concerned authorities should modify the existing policies or implement new ones in order to strengthen this sector.

\subsection{Case Studies}

Two case studies are presented in this section to provide examples of successful stories of implementation of pollution prevention programs in carpet industries. One example is taken from Australia and the other one from Nepal.

\subsection{Case Study I: Wool Scouring Industry (Australia)}

This case study is one of the best examples in which Goulburn Wool Scour (GWS) industry in Australia implemented pollution prevention strategies in many areas within the industry and experienced changes in less than two years (EMC, 1999). Wool scouring is a process by which crude wool containing grease and dirt is washed and cleaned through a series of washing and cleaning stages using processes such as de-dusting, washing with detergent and rinsing to remove lanolin from the wool. At peak production, GWS plant operates on a basis of three shifts per day and five days per week and processes around 50 tons of wool per day in two scouring lines. On an average, each ton of greasy wool contains $150 \mathrm{~kg}$ of lanolin, $40 \mathrm{~kg}$ of suint, $150 \mathrm{~kg}$ of dirt (organic and 
inorganic), $20 \mathrm{~kg}$ of vegetable matter and $640 \mathrm{~kg}$ of wool fiber. The plant implemented pollution prevention technologies in the following areas and achieved successful results as indicated below:

\section{Minimized water consumption by recycling and reusing of up to $50 \%$ of wastewater:}

As mentioned previously, the industry uses two scour lines. Each scour line generates 12,000 liters of wastewater per hour, out of which almost 10,000 liters is reused or recycled after treatment as explained here. Used water has a BOD of about 150, which is removed using algae in a 4 megaliter dam. The algae metabolizes nutrients (or BOD) that is in the water. The water is then pumped to a trickling tower and a clarifier. The treated water is then passed through a saw tooth weir and a gravity settler. This water is now ready for recycling. The water that is cleaned in such a way makes up to $50 \%$ of the rinse water requirement and costs only half the price of the fresh water obtained from the local municipality. The Nepalese carpet sector can learn from this strategy. Although Nepal is one of the richest countries in the world in terms of freshwater resources, ironically, the Kathmandu Valley, where more than 90\% of the carpet industries are situated, has been facing chronic water shortages in recent years. For instance, the valley dwellers receive water through the piped water supply system for only a few hours a day. Therefore, people in the valley use different means to supplement their daily water demand through tube wells to pump groundwater, roof-top storage tanks to collect rain water, mobile water tanks to fetch river water from outside the valley, community storage tanks, etc. One study shows that the added economic burden of such practices is almost in the range of 34 to $56 \%$ of the monthly income of some middle class households in the valley 
(Pattanayak et al., 2005). This cost does not include loss of labor hours expended in arranging such means. Therefore, if the Nepalese carpet industries can implement their own water treatment plants and reuse the water, it can significantly reduce the cost of water.

Recovery, reuse and sale of waste by-products: Approximately 1,000 tons of oil and grease is separated from the wastewater every year and sold to cosmetic companies. Each year, approximately 2,000 tons of solid sludge is separated using a decanter and a centrifuge and utilized in paddocks to convert them into organic soil. The industry produces 250,000 - 300,000 liters of treated effluent per day, which is used to irrigate 80 hectares of farm land owned by GWS. This water is equivalent to $250 \mathrm{~mm}$ of annual rainfall in Australia. It should be noted that Australia is the driest continent in the world and recovery and reuse of water plays a major role in the local and regional ecosystems of the whole country. The Nepalese carpet sector can learn from this example too. It should be noted that the Kathmandu Valley covers an area of $650 \mathrm{~km}^{2}$ with almost $40 \%$ of the land area used for agricultural purposes (Kannel et al., 2007). The carpet industries of the valley can generate similar organic soil and irrigation water and sell them to local farm lands. Since Nepal imports chemical fertilizers using foreign currency, use of organic fertilizers will help the economy. Furthermore, diversion of the wastewater from the valley rivers will also help improve the water quality situation of these rivers, which are highly contaminated (Kannel et al., 2007). 
Energy saving: By installing monitoring and control mechanisms, energy saving has been achieved in the scouring line. Scouring requires $62^{\circ} \mathrm{C}$ temperature, while rinsing requires only $52^{\circ} \mathrm{C}$. The warm effluent from the scouring line is recycled to heat the rinsing water in heat exchangers and increase its temperature. This has optimized the use of energy required for heating water and gas usage has been reduced by $25 \%$. The industry also uses innovative drying process in which heat is added in the end of drying process rather than in the beginning. Most of the conventional processes use heat for drying in the beginning of the process. GWS has been able to save $56 \%$ in energy costs in the dryer by adopting this innovative approach. This is equivalent to an annual saving of AUS \$68,000 in energy costs.

Minimizing storage, handling and transport costs: The size of the wool delivered to the plant is reduced to three times the volume by an efficient packing method so that the wool can be stored in a comparatively small storage area. These bales need to be expanded or reconditioned back to their loose state for processing. Most plants have steam boilers, which inject steam into the bales. This process softens the lanolin and allows the bales to expand back to their original size. Since GWS has no steam on-site, it has devised a system of using exhaust vapor (which is at $100 \%$ relative humidity and $65^{\circ} \mathrm{C}$ ) from the drying process for about 24 hours to expand the bales to their full size. The energy used in this process is free, as it is the waste exhaust from the dryer. The steam injection equipment used by other wool scours costs in excess of AUS $\$ 100,000$, plus the energy used to run them. 


\subsection{Case Study II: Nepalese Carpet Industry}

Overseas Trading Company Pvt. Ltd. (OTC) is one of the carpet industries situated in the Kathamandu Valley. It was established in 1975 and currently it has five other affiliated carpet industries all in the Valley. The company exports carpets mainly to Germany and has annual sales of approximately US\$2.7 million. It employs approximately 600 staff. OTC also produces wastewater effluents that contain different pollutants. In order to tackle pollution problems, preventive strategies were introduced. Its senior management took the initiative to modify dyeing and washing processes by reviewing every step in the process. A simplified flow chart that the OTC used is presented in Figure 6 (FNCCI, 2007). The program was called the Ecolabeling Project, which was technically assisted by the government of Finland. Eight carpet companies participated in this program between 1999 and 2002. A case study of implementation of this program at OTC is presented here. In particular, OTC implemented the following strategies.

Minimized the excessive use of dye: Prior to explaining how dye minimization was achieved, a brief description on dye binding chemistry at the molecular level is presented here. Wool is a natural polymer that contains different amino acids linked with peptide bonds. Figure 4 presents a simplified primary structure of a wool molecule (Tropp, 1997). In this molecule, amino $\left(\mathrm{NH}_{3}{ }^{+}\right)$and carboxylic $\left(\mathrm{COO}^{-}\right)$groups are present as two end groups, which are know as $\mathrm{N}^{+}$and $\mathrm{C}^{-}$terminals. There are many amino acids present within the polymer, which are represented by $R_{1}, R_{2}$, and $R_{n}$. In nature, there are generally 20 amino acids that make up natural polymers such as wool, bone, skin, etc. of 
all living beings. The dyes used at OTC are of anionic in nature and when they are applied under acidic condition, they bind at the $\mathrm{N}$-terminal $\left(\mathrm{N}^{+}\right)$of the wool. A simplified dye binding mechanism is presented in Figure 5 (Bruce et al., 2000). The binding of the dye to the wool has been shown to be enhanced by heating, mixing and a longer retention time as depicted by the equation $\mathrm{Q}=2 \mathrm{C}_{0}(\mathrm{Dt} / \pi)^{1 / 2}$ (Alexander and Hudson, 1950). Where, $\mathrm{Q}$ is the quantity of dye adsorbed per unit wool area, $\mathrm{C}_{0}$ is the concentration of dye in the liquid solution, $\mathrm{D}$ is the apparent diffusion coefficient of dye within the dye fiber, $\mathrm{t}$ is the retention time. The effect of all these parameters during the wool dyeing process is extensively discussed by Alexander and Hudson (1950). The traditional practice at OTC was to use dye at any concentration, temperature or retention time. This resulted in the excessive use of dye, generation of wastewater that contained alarmingly high levels of dye, and loss of resource. OTC initiated several small scale studies at their facility to understand the effect of $\mathrm{pH}$, temperature, mixing, etc. and came up with a standard procedure and started to use optimum dye quantity for effective results. This resulted into the improved product quality in terms of color fastness of the carpet. This also minimized the dye consumption (FNCCI, 2007).

\section{Minimized the use of ammonium sulfate, sodium sulfate and acetic acid: The} traditional practice at OTC was to use ammonium sulfate during the dyeing process regardless of whether it was needed or not. OTC initiated pilot scale experiments and came up with an optimum concentration of this chemical to be used for a specific dye. This resulted into 10\% saving of ammonium sulfate. Similarly, OTC carried out trial experiments on the quantity of sodium sulfate and acetic acid required for optimum 
results and reduced their quantity by $50 \%$ and $21 \%$, respectively. The financial savings achieved were equivalent to US\$1,000, 300 and 2,200 for ammonium sulfate, sodium sulfate and acetic acid, respectively. It is noted that these reductions were achieved simply by conducting experiments with the available manpower and resources at the company and without the use of any sophisticated equipment. The payback period was almost immediate in all cases. Similarly, the wastewater contained $42 \%$ less COD and $40 \%$ less TDS after reducing the use of these chemicals. Although it is not known if the current decreased COD and TDS (total dissolved solids) levels are safe for final discharge, it is definitely a significant improvement, which was only possible through such initiatives (FNCCI, 2007).

Minimized water usage and wastewater generation: OTC implemented leak detection initiative along with recycling of wastewater during washing of wool in the vats. This resulted into $1.5 \%$ saving (i.e. $4,700 \mathrm{~m}^{3}$ ) in water consumption per year (FNCCI, 2007).

The implementation of the above pollution prevention techniques also resulted into other intangible benefits such as improved working conditions and improved occupational health and safety of workers. It is noted that Nepal's carpet industry acquired negative publicity because of the child labor issue and bad working conditions inside industries. By implementing such pollution prevention programs, industries can achieve better working conditions, which will also help them regain their popularity in the overseas markets. 
As mentioned earlier, between 1999 and 2002, several carpet industries participated in the Ecolabelling Project (FNCCI, 2007). However, after almost five years since the completion of these projects, other carpet industries have not implemented such

initiatives in Nepal, despite the high level of awareness in this area. Approximate cost of implementing the pollution prevention technologies has been estimated at only US\$ 6,000 for each carpet industry in Nepal. This is a meager investment compared to what has been invested in the industry. Clearly, the lack of participation to implement such initiatives is not a result of the lack of awareness or funding.

Some of the reasons for this may be attributed to the factors associated with the socioeconomic situation of the country, apathy of the government and lack of law enforcement mechanism. Therefore, Nepal government needs to act quickly as a strict environmental regulator. It is noted that all carpet industries are registered with the government and they are all located inside the Kathmandu Valley. This makes it easier to monitor them effectively. If the regulatory mechanism becomes strict, then the industries are more likely to think on the available methodologies to curb the pollution. Since the awareness on pollution prevention already exists, industries will more likely implement it rather than face severe penalty as an offender.

\subsection{Conclusions}

Nepal's carpet sector needs immediate attention from all concerned authorities in order to revive its full potential. Although it is one of the strongest industrial sectors in terms of 
employment generation and foreign currency earnings, it is also suffering from many problems. One of the major problems is in the area of environmental performance, which has become a pressing issue. These environmental issues can be solved using end-of-pipe technologies, but such technologies are not suitable in Nepal's context. Therefore, a radical yet practical approach is required. Since pollution prevention techniques have been already tried with successful outcomes in different parts of the world, Nepal's carpet sector can also implement such methodologies to improve the current situation. Furthermore, the government should also play an important role in enforcing environmental regulations. 


\subsection{References}

Adhikary S. Small waste water treatment units for Kathmandu Valley. The Kathmandu Post, Editorial, Issue dated August 4, 2002.

Alexander P, Hudson RF. The kinetics of wool dyeing, Part I: simple acid dyes. Textile Research Journal, 2000; 20: 481-491.

Bruce RL, Broadwood NV, King DG. Kinetics of wool dyeing with acid dyes. Textile Research Journal, 2000; 70: 525-531.

CBS - Central Bureau of Statistics. Statistical Year Book of Nepal, 2003.

CCIA - Central Carpet Industries Association, Carpets of Nepal.

http://www.nepalcarpet.org/main.html. (last accessed: August 5, 2007).

CCME - Canadian Council of Ministers of the Environment, Environmental Quality Guidelines, Freshwater Aquatic Life Criteria, 2002.

CCNA - Central Carpet Industries Association. History of Carpets in Nepal, 2003.

CWDB - Carpet and Wool Development Board. Nepal Carpet Directory, 2006.

Dupont RR, Theodore L, Ganesan K. Pollution Prevention, The Waste Management Approach for the $21^{\text {st }}$ Century, Lewis Publishers,2000; 498 p.

EMC - Environmental Management Centre. Environmental management improves product quality in wool scouring, www.emc.com, 1999. (last accessed: August 5, 2007)

FNCCI - Finnish Technical Assistance to Environmental Labelling for Export Industries in Nepal 1999-2002. http://www.fncci.org/ecolabelproject, 2007. (last accessed: August 5, 2007)

Gautam R, Herat S. Environmental issues in Nepal and solving them using the cleaner production approach, Journal of Cleaner Production, 2000;8:225-232.

Green MG. The effects of carpet dye on the Bagmati River. M.Sc. Thesis, Massachusetts Institute of Technology, 69p, 2003.

Hammer B. Chemical substitution in the Nepal carpet industry, Journal of Industrial Ecology, 1998;2(4):7-9.

Hendrickson CT, Lave LB, Matthews HS. Environmental Life Cycle Assessment of Goods and Services An Input-Ouput Approach, RFF Press, 2006;260 p. 
JICA - Japan International Cooperation Agency, Country Profile on Environment Nepal. Annual Report, 1998.

Kannel PR, Lee S, Kanel SR, Khan SP. Chemometric application in classification and assessment of monitoring locations of an urban river syste., Analytica Chimica Acta, 2007;582:390-399.

Karn SK, Harada H. Surface water pollution in three urban territories of Nepal, India, and Bangladesh. Environmental Management, 2001;28(4):483-496.

KP - Kathmandu Post Carpet Export Rises, News posted on July 25, 2005.

Metcalf \& Eddy, Paper presented at a Seminar on Groundwater and Waste Water, organised by Melamchi Water Supply Development Board, 14 February 2000, Kathmandu, Nepal, 2000.

MOF - Ministry of Finance, Economic Survey of Nepal, 2005.

MOPE - Ministry of Population and Environment of Nepal, Generic Standard Part I Tolerance Limits for Industrial Effluents to be Discharged into Inland Surface Waters, 1995.

Newar N. Quality not quantity, Nepal's rug industry has staged a dramatic comeback and this time it is with value, not volume, Nepali Times, Issue\# 226, 17-23 December, 2004.

NPEDC - National Productivity and Economic Development Centre Subsector Studies. Study on assessment of problems of carpet washing in Nepal, study sponsored by partnership programme/ZDH Technonet Asia, Singapore, 1991.

Pattanayak SK, Yang JC. Coping with unreliable public water supplies: averting expenditures by households in Kathmandu, Nepal. Water Resources Research, 2005;41: doi:10.1029/2003WR002443, W02012, pp. 2-12.

Pradhan BK. Status of water quantity and quality in Nepal, Community Health Family Health Department, Presentation, 2000.

Sharma S, Bajracharya RM, Sitaula BK, Merz J. Water quality in the central Himalaya. Current Science, 2005;89(5):774-786.

Sitaula R. The Nepalese Carpet Industry, http://www.panasia.org.sg/nepalnet/economics/carpets.htm, 2003. (last accessed: August 5, 2007).

Thornton J. Water Loss Control Manual, McGraw-Hill, 645 p., 2002.

TRN - The Rising Nepal, Polluting Carpet Industry, Editorial April 30, 2003. 
Tropp BE., Biochemistry Concepts and Applications, Brooks/Cole Publishing, 1997, 840p.

UNIDO - United Nations Industrial Development Organization, Industrial Development Perspective Plan, Vision 2020, Strategy Paper Prepared for HMG/Nepal by UNIDO on behalf of UNDP, 320 p, 2002.

USDOL - United States Department of Labor, Child Labor Report on Nepal, 6 p, 2003.

WB/FNCCI - World Bank/Federation of Nepalese Chambers of Commerce and Industry, The Business Environment and Manufacturing Performance in Nepal, Kathmandu:

Federation of Nepalese Chambers of Commerce and Industry, 2000. 